\section{Ultrasound evaluation of digital flexor tendons of jumping horses undergoing treadmill training}

\author{
Avaliação ultrassonográfica dos tendões flexores digitais de \\ equinos de salto em treinamento na esteira ergométrica
}

\author{
Ananda Parra Buzzetti*, Isabella Torres Nothaft', Júlio César Paganela², Bruna Caroline Franzan³, \\ Gabriel Isola Braga', Anna Paula Balesdent Barreira ${ }^{4}$, Leonardo Rodrigues de Lima ${ }^{4}$, \\ Fernando Queiroz de Almeida ${ }^{4}$ \\ ' Veterinarian, MSc. Curso de Pós-Graduação em Medicina Veterinária, Departamento de Medicina e Cirurgia Veterinária \\ (DMCV), Instituto de Veterinária (IV), Universidade Federal Rural do Rio de Janeiro (UFRRJ). Campus Seropédica, RJ, Brazil. \\ 2 Veterinarian, EquiClinic, Rio de Janeiro, RJ, Brazil \\ ${ }^{3}$ Animal Scientist, DSc. Programa de Pós-Graduação em Ciência Animal. Instituto de Ciência Animal, UFRRJ, Campus \\ Seropédica, RJ, Brazil. \\ ${ }^{4}$ Veterinarian, DSc. DMCV, IV, UFRRJ. Campus Seropédica, RJ, Brazil.
}

\begin{abstract}
This study aimed to perform ultrasonographic evaluation of the digital flexor tendons of jumping horses undergoing complementary training on a treadmill. Fifteen Brazilian Sport horses were divided into two groups: Group I with 7 animals in physical training complementary to the standard training at the Brazilian Army's Riding School; and Group II with 8 animals in standard training used in the Brazilian Army's Riding School. Complementary training was performed on a treadmill on an inclined plane. Ultrasonographic images were taken at the beginning and at the end of training. The left thoracic and pelvic limbs of horses were evaluated for echogenicity values and cross-sectional areas of the superficial digital flexor tendons (SDFTs) and deep digital flexor tendons (DDFTs) in zones IA, IIB, and IIIB. The mean areas of the SDFT were $93.7 \mathrm{~mm}^{2}$ and $95.8 \mathrm{~mm}^{2}$ at the beginning and the end of training, respectively. The cross-sectional area of DDFT increased from $124.6 \mathrm{~mm}^{2}$ at the beginning of training to $136.8 \mathrm{~mm}^{2}$ at the end of training. The echogenicity values of both tendons were between 0 and 1 as expected, concluding that clinically, the animals showed adaptation to the exercise protocol with no signs of tendon injury being detected, implying that traditional training and complementary training are safe.
\end{abstract}

Keywords: horses, locomotor, riding.

\section{Resumo}

Esta pesquisa teve como objetivo proceder avaliações ultrassonográficas dos tendões flexores digitais de equinos em treinamento complementar em esteira ergométrica. Foram utilizados 15 equinos da raça Brasileiros de Hipismo (BH), divididos em dois grupos: Grupo I, com sete animais em treinamento físico complementar ao treinamento padrão da Escola de Equitação do Exército; Grupo II, com oito animais em treinamento padrão utilizados na Escola de Equitação do Exército. O treinamento complementar foi executado na esteira ergométrica, em plano inclinado. As imagens ultrassonográficas foram realizadas no início e no final do treinamento. Foram avaliados os membros locomotores torácico e pélvico esquerdos dos equinos quanto a ecogenicidade e a área da seção transversal dos tendões flexores digitais superficiais (TFDS) e tendões flexores digitais profundos (TFDP), nas zonas IA, IIB e IIIB. A média da área dos TFDS foi de $93,7 \mathrm{~mm}^{2}$ e de $95,8 \mathrm{~mm}^{2}$, no início e no final do treinamento, respectivamente. ODDFT apresentou um aumento da área da seção transversa, de 124,6 $\mathrm{mm}^{2}$ no início do treinamento e, de 136,8 $\mathrm{mm}^{2}$ no final do treinamento. A ecogenicidade de ambos os tendões se apresentou entre 0 e 1, como esperado, concluindo-se que clinicamente os animais apresentaram adaptação ao exercício atribuído, não sendo detectados sinais de lesões tendíneas, qualificando o treinamento tradicional e o treinamento complementar como seguros.

Palavras-chave: cavalos, locomotor, hipismo.

\section{Introduction}

Horses are usually trained to increase their musculoskeletal strength, which would further increase their resistance to injury. However, many injuries are preceded by failure of muscle or tendon tissue to adapt to exercise, imbalance between subclinical damage and cellular repair activity, or both (Hodgson et al., 2014; Pugliese et al., 2020).
How to cite: Buzzetti, A. P., Nothaft, I. T., Paganela, J. C., Franzan, B. C., Braga, G. I., Barreira, A. P. B. Lima, L. R., \& Almeida, F. Q. (2O22). Ultrasound evaluation of digital flexor tendons of jumping horses undergoing treadmill training. Brazilian Journal of Veterinary Medicine, 44, e004421. https://doi.org/10.29374/2527-2179.bjvm004421

Received: October 28, 2021

Accepted: February 01, 2022

\section{*Correspondence}

Ananda Parra Buzzetti

Curso de Pós-graduação em Medicina

Veterinária, Departamento de Medicina e Cirurgia Veterinária - DMCV, Instituto de

Veterinária - IV, Universidade Federal Rural do Rio de Janeiro - UFRRJ

Rodovia BR 465, Km 07- Zona Rural,

Seropédica- RJ, 23890-000

E-mail:ananda_buzzetti@hotmail.com 
Treadmill has been used in the training and evaluation of horses in controlled temperatures and environments, facilitating the standardization of results. The slope of the treadmill shifts the horse's weight backward, thus promoting the overload on the pelvic limbs of the horse and increasing the force exerted by these limbs. Inadequate training or an exacerbated jumping routine during the physical conditioning of horses can have consequences on animal health and welfare, loss of the riding training and invested income and consequently, on the value of the horse industry (Hodgson et al., 2014).

This research was conducted to evaluate jumping horses undergoing complementary training on an inclined plane on a treadmill using ultrasonographic evaluations of the superficial (SDFT) and deep digital flexor tendons (DDFT) in the thoracic and pelvic limbs as parameters.

\section{Material and methods}

\section{Animals and experimental design}

Fifteen Brazilian Sport horses were included with a mean age of $12 \pm 4$ years and a mean body weight of $498 \pm 58 \mathrm{~kg}$. The study was conducted using a completely randomized design with 2 treatments and 8 replications. The horses were divided into two groups. In Group I ( $=7$ ), the horses were subjected to physical training complementary to the standard training at the Army Riding School. In Group II ( $\mathrm{n}=8$ ), the horses underwent the standard training used in the Army Riding School.

\section{Trial period and training protocol}

The protocol for training jumping horses at the Army Riding School consisted of outdoor activities, gymnastics, flexion, and jumping courses. The horses were subjected to a daily training sequence lasting 50 minutes. The experimental period lasted 16 weeks (Figure 1). The horses were subjected to clinical examination to assess their health before the beginning of the study.

Horses in the complementary training group (Group I) were adapted to the treadmill (Galloper 5500. Sahinco ${ }^{\circledast}$ ) for 3 weeks. Complementary training was performed during the 16 weeks of standard training and was divided into two phases:

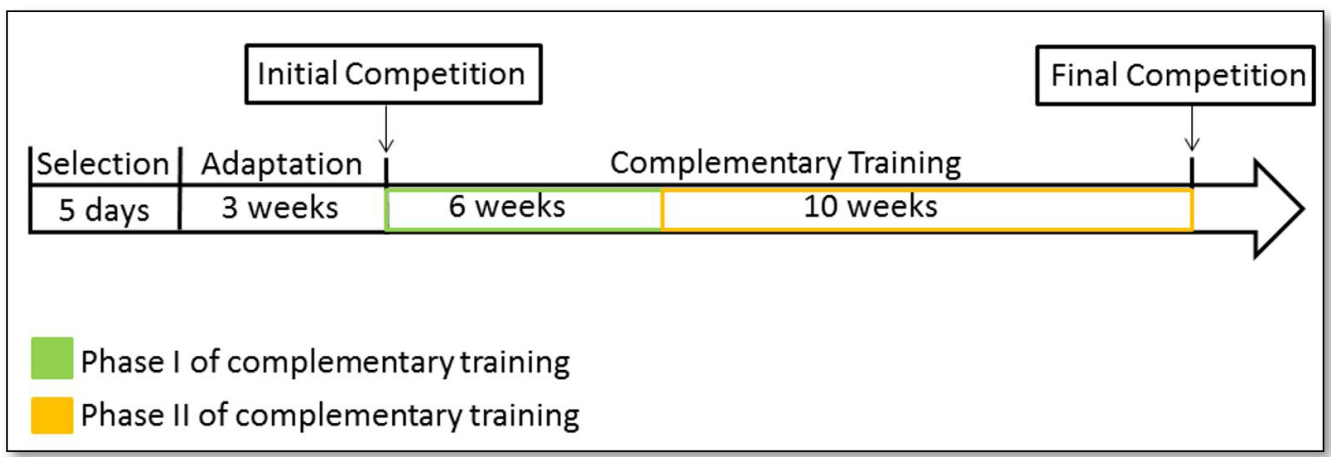

Figure 1. Experimental protocol scheme.

\section{Phase I of complementary training}

This initial phase lasted for six weeks. The horses started an exercise protocol performed on the treadmill twice a week, at 3-day intervals. On the first day, training consisted of warming up to stepping $(1.7 \mathrm{~m} / \mathrm{s})$ on the treadmill without incline for 4 minutes, then to trotting $(3.8 \mathrm{~m} / \mathrm{s})$ for 6 minutes with the last 3 minutes with the treadmill at $3 \%$ slope. Afterwards, the horses followed the step on the treadmill without inclination for 2 minutes and 2 minutes per step on the treadmill at 7\% slope, ending the protocol with five minutes per step on the treadmill without inclination. On this day, the horses covered 2,694 meters in 19 minutes. On the second day, training began with the same warm-up pattern. Subsequently, the horses followed three exercise sessions at a step $(1.7 \mathrm{~m} / \mathrm{s})$ for 4 minutes each session. In each session, the horses walked on the treadmill 
without inclination for 2 minutes and 2 minutes with the treadmill at a 7\% slope. Finally, the horses followed a five-minute walk on an uninclined treadmill. The horses covered 3,510 meters in 27 minutes of training on the second day.

\section{Phase II of complementary training}

This phase lasted for 10 weeks, and the intensity of the exercises was increased. The horses were subjected to an exercise protocol performed on the treadmill twice a week at 3-day intervals. The training started with the same warm-up pattern as in Phase I. Subsequently, the horses underwent three brisk exercise sessions $(1.7 \mathrm{~m} / \mathrm{s})$ for five minutes each session. In the first session with the horses, they walked on the treadmill without inclination for two minutes and three minutes with the treadmill at 7\% slope. In the following two sessions, the periods of walking exercises were similar; however, the treadmill was inclined at 13\% slope in the final three minutes of each session. On the treadmill, the horses covered 3,714 meters in 29 minutes of training, twice a week. At the end of the training, the horses continued to cool down for five minutes at a pace on the treadmill without incline.

\section{Ultrasonography of the superficial and deep tendons in the locomotors}

Ultrasound images were obtained before and after the training. Ultrasound imaging was performed with the horses in a station at rest on a flat floor using the Digiprince DP-4900 Vet ultrasound, with $7.5 \mathrm{MHz}$ convex mechanical transducer. Trichotomy was performed followed by the application of an aqueous-based gel and dynamic scanning of the left thoracic and pelvic limbs. If necessary, the horse was sedated with Detomidin ${ }^{\circledR} 1 \%$, intravenously at a reduced dose of $0.1 \mathrm{ml} / 100 \mathrm{~kg}$ for the safety of the team, equipment, and the horse. To ensure consistency of the results, a single specialist veterinarian performed all ultrasound scans using the image analysis system and was blinded to the treatments.

The characterization of the positioning for evaluating the tendons of the metacarpal region was divided into zones (Figure 2), related in a proximal-distal manner, selected in the following positions: IA, IIB, and IIIB. Images were obtained in sequence, in zone IA, located $2 \mathrm{~cm}$ distal to the base of the accessory carpal bone (BACB); in zone IIB, $14 \mathrm{~cm}$ from BACB; and in zone IIIB, $22 \mathrm{~cm}$ from BACB (Genovese et al., 1997). Six images were obtained before and after training: thoracic

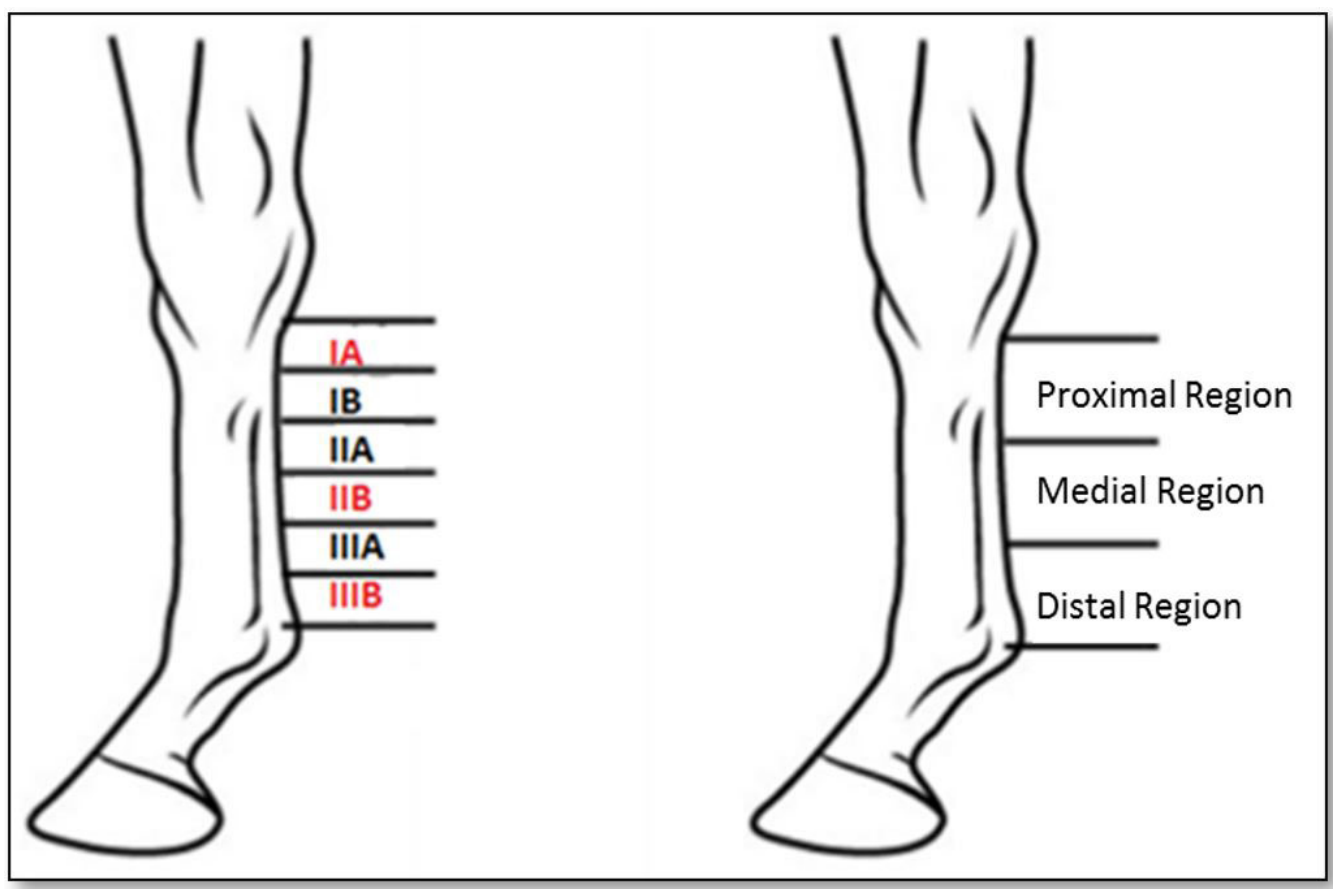

Figure 2. Zones of the metacarpal/metatarsal region assessed on ultrasonography. 
limbs IA, IIB, and IIIB, and pelvic limbs IA, IIB, and IIIB. In the image analysis, the following patterns were used: tendon echogenicity $(\mathrm{O}=$ echoic $; 1=$ echoic predominance; $2=50 \%$ echoic and $50 \%$ anechoic; 3 = anechoic predominance; 4 = totally anechoic) (Yamada et al., 2009). Echogenicity was evaluated using "in the dark" reports under the analysis of two experienced veterinarians in the area. The cross-sectional areas of the tendons were measured on ultrasound images using the Image J software, and the values are expressed in $\mathrm{mm}^{2}$.

\section{Statistical analysis}

The evaluation results were compiled using the Microsoft ${ }^{\circledast}$ Office Excel 2007 spreadsheets. The mean values of the areas of the tendons were analyzed in a split-plot scheme with the plots representing the moments of training (before and after training) and in the subplots as with and without complementary training. The results were subjected to analysis of variance and means were compared using Tukey's test ( $\mathrm{P}<0.05)$. Echogenicity values were evaluated using Bonferroni's non-parametric test $(\mathrm{P}<0.05)$. Statistical analyses were performed using R software version 3.6.3.

\section{Results}

Ultrasonographic measurements were performed in the cross-sectional areas of the flexor tendons in the thoracic and pelvic limbs at the beginning and the end of training (Figures 3 and 4 ). The mean cross-sectional areas of the SDFT and deep flexor tendon (DDFT) of the thoracic limbs are shown in Tables 1 and 2 , respectively.

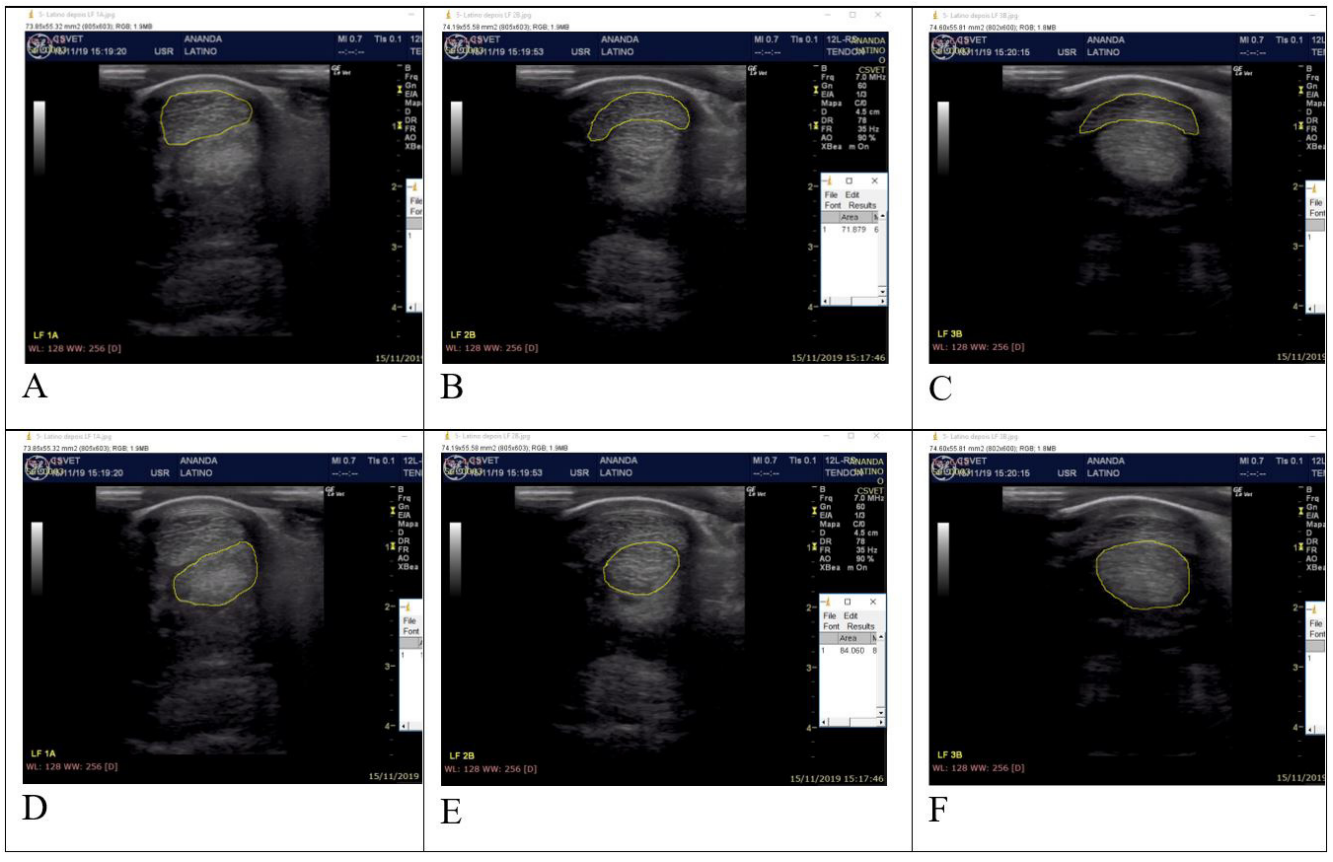

Figure 3. Cross-sectional areas of the tendons of the thoracic limb, in the respective areas. A- SDFT area in zone IA. B- SDFT area in zone IIB. C- SDFT area in zone IIIB. D- DDFT area in zone IA. E- DDFT area in zone IIB. F- DDFT area in zone IIIB.

The mean values of the cross-sectional area of the SDFT and deep flexor tendon (DDFT) of the pelvic limb are shown in Tables 3 and 4, respectively.

The mean values of echogenicity of the SDFT and deep flexor tendon (DDFT) in zones IA, IIB, and IIIB of the thoracic limb at the beginning and the end of training are shown in Tables 5 and 6 .

The mean echogenicity values of the SDFT and deep flexor tendon (DDFT) in zones IA, IIB, and IIIB of the pelvic limb are shown in Tables 7 and 8, respectively. 


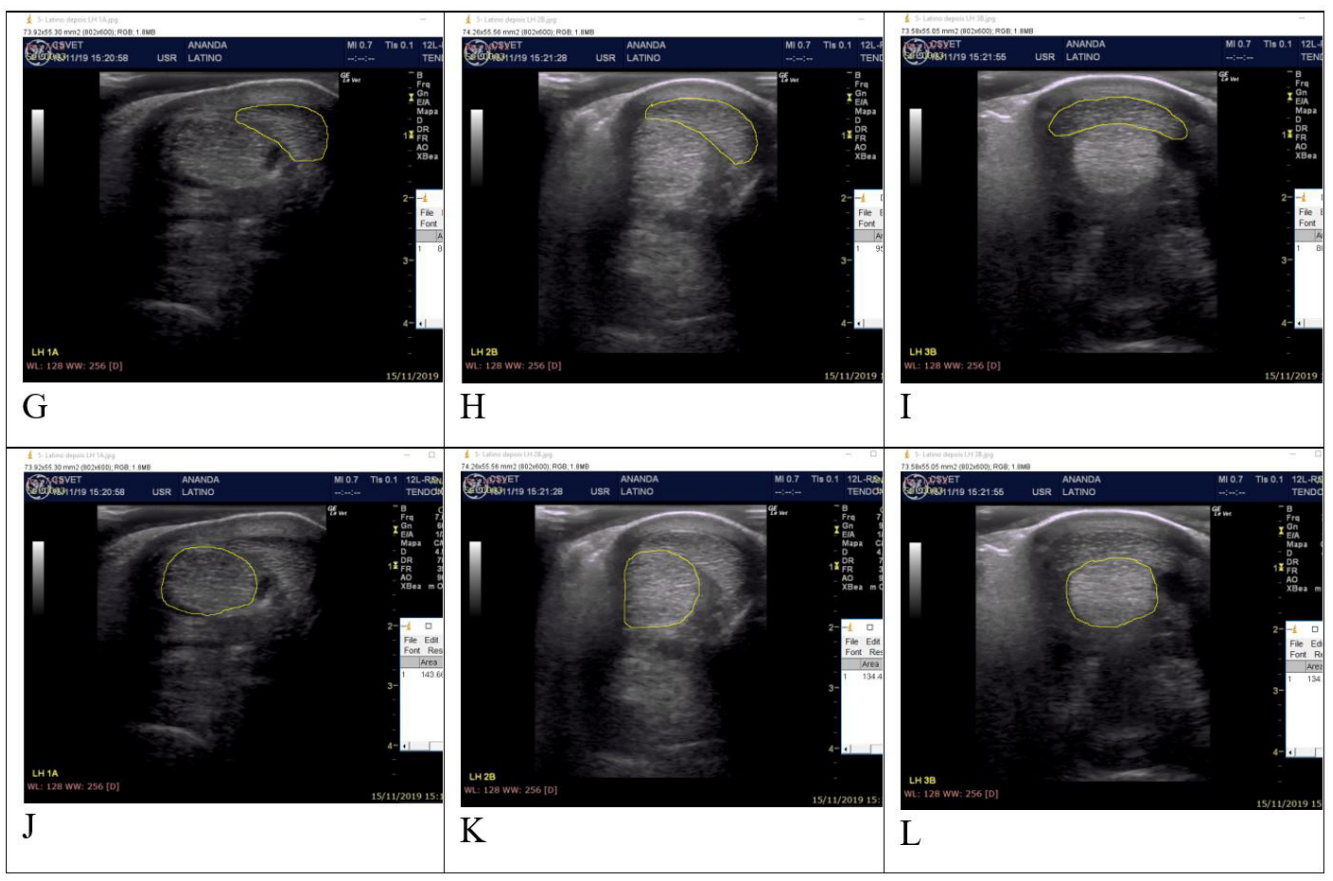

Figure 4. Cross-sectional areas of the pelvic limb tendons, in the respective areas. G- SDFT area in zone IA. $\mathrm{H}$ - SDFT area in zone IIB. I- SDFT area in zone IIIB. J- DDFT area in zone IA. K- DDFT area in zone IIB. L- DDFT area in zone IIIB.

Table 1. Mean values of the cross-sectional area of the superficial digital flexor tendon (SDFT) of the thoracic limb of horses.

\begin{tabular}{|c|c|c|c|}
\hline \multirow{3}{*}{ Treadmill } & \multicolumn{2}{|c|}{ Area SDFT $\left(\mathrm{mm}^{2}\right)$ thoracic limb } & \multirow{3}{*}{ p value } \\
\hline & \multicolumn{2}{|c|}{ Training } & \\
\hline & Begining & End & \\
\hline & …………........... & 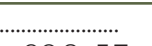 & \multirow{3}{*}{0.5615} \\
\hline Yes & $94.9 \pm 11.6$ & $90.8 \pm 5.7$ & \\
\hline No & $102.2 \pm 18.0$ & $106.0 \pm 15.2$ & \\
\hline Yes & $91.1 \pm 6.6$ & $92.6 \pm 6.9$ & \multirow{3}{*}{0.9297} \\
\hline No & $91.6 \pm 9.6$ & $94.1 \pm 17.2$ & \\
\hline & 9) $7+100$ & $907+56$ & \\
\hline No & $\begin{array}{l}92 . / \pm 10.0 \\
98.8 \pm 13.3\end{array}$ & $\begin{array}{l}90 . / \pm 5.6 \\
105.6 \pm 18.4\end{array}$ & 0.4801 \\
\hline
\end{tabular}

Table 2. Mean values of the cross-sectional area of the deep digital flexor tendon (DDFT) of the thoracic limb of horses.

\begin{tabular}{|c|c|c|c|}
\hline \multirow{3}{*}{ Treadmill } & \multicolumn{2}{|c|}{ Area DDFT $\left(\mathrm{mm}^{2}\right)$ thoracic limb } & \multirow{3}{*}{$\mathrm{p}$ value } \\
\hline & \multicolumn{2}{|c|}{ Training } & \\
\hline & Begining & End & \\
\hline & \multicolumn{2}{|c|}{ Zone I A. } & \multirow{3}{*}{0.3862} \\
\hline Yes & $117.4 \pm 10.2$ & $118.4 \pm 20.9$ & \\
\hline No & $113.8 \pm 17.7$ & $108.5 \pm 18.6$ & \\
\hline Yes & \multicolumn{2}{|c|}{ Zone II B .............................. } & \multirow{3}{*}{0.4021} \\
\hline No & $96.3 \pm 10.7$ & $108.1 \pm 17.8$ & \\
\hline & …... & & \\
\hline Yes & $133.1 \pm 17.0$ & $133.3 \pm 5.6$ & \multirow{2}{*}{0.7352} \\
\hline No & $146.3 \pm 13.2$ & $142.5 \pm 15.8$ & \\
\hline
\end{tabular}


Table 3. Mean values of the cross-sectional area of the superficial digital flexor tendon (SDFT) of the pelvic limb of horses.

\begin{tabular}{|c|c|c|c|}
\hline \multirow{3}{*}{ Treadmill } & \multicolumn{2}{|c|}{ Area SDFT $\left(\mathrm{mm}^{2}\right)$ pelvic limb } & \multirow{3}{*}{ p value } \\
\hline & \multicolumn{2}{|c|}{ Training } & \\
\hline & Begining & End & \\
\hline & \multicolumn{2}{|c|}{ 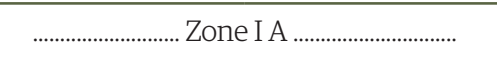 } & \\
\hline Yes & $95.5 \pm 19.4$ & $86.2 \pm 7.9$ & \multirow{2}{*}{0.0936} \\
\hline \multirow[t]{2}{*}{ No } & $87.6 \pm 13.3$ & $104.5 \pm 17.9$ & \\
\hline & 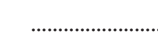 & $\ldots \cdots \cdots \cdots \cdots \cdots \cdots$ & \multirow{3}{*}{0.9476} \\
\hline Yes & $94.2 \pm 7.7$ & $91.8 \pm 4.7$ & \\
\hline \multirow[t]{2}{*}{ No } & $93.1 \pm 18.4$ & $90.0 \pm 7.2$ & \\
\hline & $\ldots$ & $\ldots \ldots \ldots \ldots \ldots \ldots \ldots$ & \\
\hline Yes & $96.1 \pm 7.0 \mathrm{a}$ & $86.5 \pm 6.3 \mathrm{a}$ & \multirow{2}{*}{0.0119} \\
\hline No & $87.2 \pm 10.0 \mathrm{a}$ & $100.2 \pm 10.4 b$ & \\
\hline
\end{tabular}

Means followed by different letters in the lines differ according to Tukey's test $(P<0.05)$

Table 4. Mean values of the cross-sectional area of the deep digital flexor tendon (DDFT) of the pelvic limb of horses.

\begin{tabular}{|c|c|c|c|}
\hline \multirow{3}{*}{ Treadmill } & \multicolumn{2}{|c|}{ Area DDFT $\left(\mathrm{mm}^{2}\right)$ pelvic limb } & \multirow{3}{*}{$\mathrm{p}$ value } \\
\hline & \multicolumn{2}{|c|}{ Training } & \\
\hline & Begining & End & \\
\hline \multicolumn{4}{|c|}{ 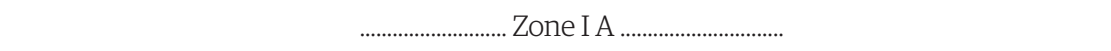 } \\
\hline Yes & $122.6 \pm 21.3$ & $124.8 \pm 24.9$ & \multirow{2}{*}{0.3869} \\
\hline No & $129.7 \pm 21.3$ & $132.0 \pm 24.1$ & \\
\hline \multicolumn{4}{|c|}{ 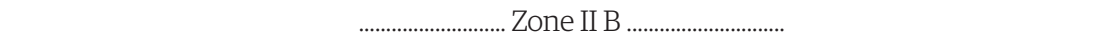 } \\
\hline Yes & $139.6 \pm 30.9$ & $132.6 \pm 19.4$ & \multirow{2}{*}{0.7627} \\
\hline No & $129.1 \pm 12.2$ & $129.6 \pm 17.9$ & \\
\hline \multicolumn{4}{|c|}{ 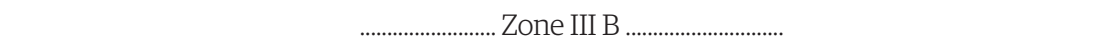 } \\
\hline Yes & $130.9 \pm 27.9$ & $141.0 \pm 12.7$ & \multirow{2}{*}{0.5766} \\
\hline No & $140.3 \pm 14.3$ & $141.0 \pm 18.8$ & \\
\hline
\end{tabular}

Table 5. Mean values of echogenicity of the Superficial Digital Flexor Tendon (SDFT) in zones IA, IIB and IIIB of the thoracic limb of horses.

\begin{tabular}{|c|c|c|c|c|}
\hline \multirow{3}{*}{ Treadmill } & \multicolumn{4}{|c|}{ Echogenicity SDFT of thoracic limb (Scala 0-4) } \\
\hline & \multicolumn{3}{|c|}{ Training } & \multirow{2}{*}{ P value } \\
\hline & Begining & End & Mean & \\
\hline \multicolumn{5}{|c|}{ 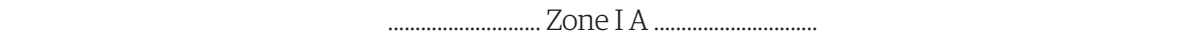 } \\
\hline Yes & $0.30 \pm 0.4$ & $0.20 \pm 0.3$ & $0.25 \pm 0.4$ & \multirow{2}{*}{0.2651} \\
\hline No & $0.07 \pm 0.2$ & $0.14 \pm 0.2$ & $0.11 \pm 0.2$ & \\
\hline \multicolumn{5}{|c|}{........................... Zone II B .............................. } \\
\hline Yes & 0.00 & $0.10 \pm 0.2$ & $0.05 \pm 0.2 b$ & \multirow{3}{*}{0.0362} \\
\hline No & $0.21 \pm 0.3$ & $0.43 \pm 0.3$ & $0.32 \pm 0.3 a$ & \\
\hline Mean & $0.13 \pm 0.2 \mathrm{a}$ & $0.29 \pm 0.3 a$ & 0.6602 & \\
\hline \multicolumn{5}{|c|}{ Zone III B .............................. } \\
\hline Yes & $0.10 \pm 0.2$ & $0.30 \pm 0.4$ & $0.20 \pm 0.3$ & \multirow{2}{*}{0.4776} \\
\hline No & $0.36 \pm 0.5$ & $0.29 \pm 0.3$ & $0.32 \pm 0.4$ & \\
\hline
\end{tabular}

Means followed by different letters in the column differ according to Tukey's test $(P<0.05)$ 
Table 6. Mean values of echogenicity of the Deep Digital Flexor Tendon (DDFT) in zones IA, IIB and IIIB of the thoracic limb of horses.

\begin{tabular}{|c|c|c|c|c|}
\hline \multirow{3}{*}{ Treadmill } & \multicolumn{4}{|c|}{ Echogenicity DDFT of thoracic limb (Scala 0-4) } \\
\hline & \multicolumn{3}{|c|}{ Training } & \multirow{2}{*}{ P value } \\
\hline & Begining & End & Mean & \\
\hline \multicolumn{5}{|c|}{ 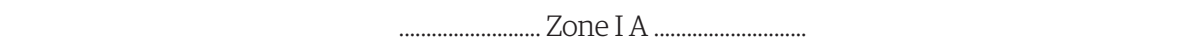 } \\
\hline Yes & $0.10 \pm 0.2$ & $0.10 \pm 0.2$ & $0.10 \pm 0.2$ & 0.2482 \\
\hline No & $0.29 \pm 0.5$ & 0.00 & $0.14 \pm 0.4$ & \\
\hline \multicolumn{5}{|c|}{ Zone II B ................................ } \\
\hline Yes & $0.10 \pm 0.2$ & $0.20 \pm 0.3$ & $0.15 \pm 0.2$ & 0.6967 \\
\hline No & $0.14 \pm 0.2$ & $0.36 \pm 0.5$ & $0.25 \pm 0.4$ & \\
\hline \multicolumn{5}{|c|}{ 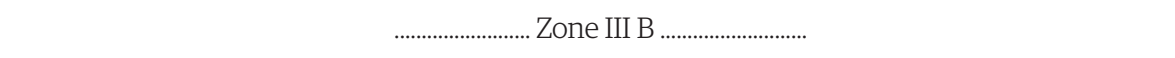 } \\
\hline Yes & $0.30 \pm 0.4$ & $0.20 \pm 0.3$ & $0.25 \pm 0.4$ & 0.6305 \\
\hline No & $0.29 \pm 0.4$ & $0.36 \pm 0.4$ & $0.32 \pm 0.4$ & \\
\hline
\end{tabular}

Table 7. Average values of echogenicity of the Superficial Digital Flexor Tendon (SDFT) in zones IA, IIB and IIIB of the pelvic limb of horses.

\begin{tabular}{|c|c|c|c|c|}
\hline \multirow{3}{*}{ Treadmill } & \multicolumn{4}{|c|}{ Echogenicity SDFT of pelvic limb (Scala 0-4) } \\
\hline & \multicolumn{3}{|c|}{ Training } & \multirow{2}{*}{ Pvalue } \\
\hline & Begining & End & Mean & \\
\hline \multicolumn{5}{|c|}{ 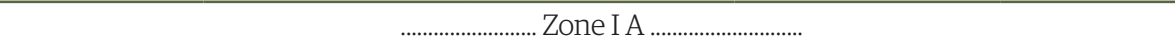 } \\
\hline Yes & $0.30 \pm 0.3$ & $0.30 \pm 0.3$ & $0.30 \pm 0.3$ & \multirow[t]{2}{*}{0.2427} \\
\hline No & $0.07 \pm 0.2$ & $0.43 \pm 0.4$ & $0.25 \pm 0.4$ & \\
\hline \multicolumn{5}{|c|}{ 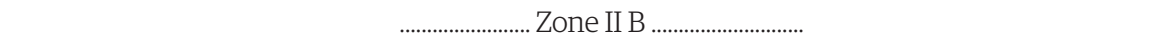 } \\
\hline Yes & $0.20 \pm 0.3 b$ & $0.40 \pm 0.2 \mathrm{a}$ & & \multirow[t]{2}{*}{0.0416} \\
\hline No & $0.43 \pm 0.3 \mathrm{a}$ & $0.29 \pm 0.3 b$ & & \\
\hline \multicolumn{5}{|c|}{ 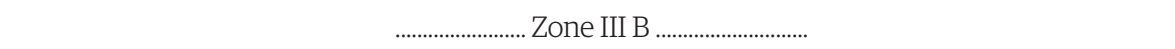 } \\
\hline Yes & $0.30 \pm 0.4$ & $0.20 \pm 0.3$ & $0.25 \pm 0.4$ & \multirow[t]{2}{*}{0.6754} \\
\hline No & $0.21 \pm 0.3$ & $0.29 \pm 0.6$ & $0.25 \pm 0.4$ & \\
\hline
\end{tabular}

Means followed by different letters in the columns differ according to Tukey's test $(P<0.05)$

Table 8. Mean values of echogenicity of the Deep Digital Flexor Tendon (DDFT) in zones IA, IIB and IIIB of the pelvic limb of horses.

\begin{tabular}{|c|c|c|c|c|}
\hline \multirow{3}{*}{ Treadmill } & \multicolumn{4}{|c|}{ Echogenicity DDFT of pelvic limb (Scala 0-4) } \\
\hline & \multicolumn{3}{|c|}{ Training } & \multirow{2}{*}{ Pvalue } \\
\hline & Begining & End & Mean & \\
\hline & & Zone I A ... & & \\
\hline Yes & $0.70 \pm 0.8$ & $0.70 \pm 0.3$ & $0.70 \pm 0.5 \mathrm{a}$ & 0.9368 \\
\hline \multirow[t]{2}{*}{ No } & $0.57 \pm 0.6$ & $0.50 \pm 0.5$ & $0.54 \pm 0.5 \mathrm{a}$ & \\
\hline & & Zone II B .. & & \\
\hline Yes & $0.30 \pm 0.4$ & $0.20 \pm 0.3$ & $0.25 \pm 0.4$ & 0.5858 \\
\hline \multirow[t]{2}{*}{ No } & $0.36 \pm 0.5$ & $0.29 \pm 0.3$ & $0.32 \pm 0.4$ & \\
\hline & & Zone III B & & \\
\hline Yes & $0.60 \pm 0.2$ & $0.20 \pm 0.3$ & $0.40 \pm 0.3 \mathrm{a}$ & 0.0284 \\
\hline No & $0.43 \pm 0.5$ & $0.21 \pm 0.3$ & $0.32 \pm 0.4 \mathrm{a}$ & \\
\hline Mean & $0.50 \pm 0.4 \mathrm{a}$ & $0.21 \pm 0.3 b$ & 0.5197 & \\
\hline
\end{tabular}




\section{Discussion}

The ability of the tendon to respond adaptively to exercise is associated with an increase in the cross-sectional area of some tendons and tendinous regions (Lyra et al., 2011). Gillis (1997) observed that tendon enlargement culminates in adaptation to physical training. Yamada et al. (2009) and Sousa et al. (2021) agree that training is directly linked to an increase in the crosssectional area in some tendons and tendinous regions. The present work corroborates previous studies in some specific zones of evaluation: the increase of the DDFT is more accentuated and visible when at the end of the training.

Regarding riding horses, Pasin et al. (2001) observed mean SDFT values of $114.73 \mathrm{~mm}^{2}$ in the IA region, $108.21 \mathrm{~mm}^{2}$ in the IIB region, and $119.16 \mathrm{~mm}^{2}$ in region IIIB. The same relationship was observed by Pasin et al. (2001), which is consistent with that seen in the present studyin which the mean area values are greater than those cited by Agut et al. (2009). There was an increase in the values for animals related to DDFT in riding horses in the study by Pasin et al. (2001), which were represented by areas of $124.96 \mathrm{~mm}^{2}$ in the IA region, $111.38 \mathrm{~mm}^{2}$ in the IIB region, and $150.82 \mathrm{~mm}^{2}$ in region IIIB. The largest areas were observed in the DDFT according to Pasin et al. (2001), which was also found in the present study. In the present work, the SDFT is $94.7 \mathrm{~mm}^{2}$, while for the DDFT, it was around $130.7 \mathrm{~mm}^{2}$.

Regarding the area of the tendons, Agut et al. (2009) evaluated only tendons of the thoracic limb and concluded that the mean areas of DDFT were significantly higher than those of the SDFT with SDFT values of $78.58 \mathrm{~mm}^{2}$ in the IA region, $70.15 \mathrm{~mm}^{2}$ in the IIB region, and $106.93 \mathrm{~mm}^{2}$ in region IIIB and DDFT values of $91.67 \mathrm{~mm}^{2}$ in the IA region, $88.48 \mathrm{~mm}^{2}$ in the IIB region, and $131.8 \mathrm{~mm}^{2}$ in region IIIB. In this study, values were above the average described by Agut et al. (2009); however, it was similarly verified that region IIB has the smallest area among the three studied zones. There was no difference in the areas of the tendons of horses in complementary training on the treadmill ( $p>0.05$ ) in the mean results of the cross-sectional areas in zones IA, IIB, and IIIB of the SDFTs and DDFTs of the thoracic limb. Significant differences were observed in the SDFT cross-sectional area and in the pelvic limb in zone IIIB in horses in training in their respective training times $(\mathrm{p}=0.0119)$. However, no significant differences were observed in the pelvic limb area according to DDFT ( $\mathrm{p}>0.05$ ).

The increase in the cross-sectional area of the DDFT in the pelvic limb was even more evident in jumping horses. Parks (2003) explained that during the impact to the ground and during the descent of the fetlock in a canter, the DDFT sustains the forces applied to the interphalangeal joints and is responsible for preventing excessive extension. Furthermore, during the jump, engagement of the pelvic limbs is one of the main factors for the elaboration of an ideal parabola, a fact that is better engaged when there is adaptability and conditioning aimed at the pelvic limbs. The engagement of the pelvic limbs improves the displacement impulse, followed by well-conditioned musculature, which is responsible for transferring all the force generated by the pelvic limbs (Oliveira et al., 2019).

The adaptation of tendons, especially in the pelvic limbs, is visible in the present study, and is very important for best performance in practice. Barreira et al. (2002) conducted a study with horses that were at the beginning of the taming process, preparatory to gallop training. The study focused on the SDFT and presented area values between $78.0 \mathrm{~mm}^{2}$ and $165.0 \mathrm{~mm}^{2}$ in the group with properties with high rates of tendinitis and areas between $68.0 \mathrm{~mm}^{2}$ and $122.0 \mathrm{~mm}^{2}$ in the group of farm with different animals. Thus, Barreira et al. (2002) concluded that tendon enlargement was associated with exercise adaptation and individual animal characteristics. The present research work involves regularly trained animals and corroborates the conclusion of Barreira et al. (2002), which showed marked standard deviation in some areas, but remained within the range found in the authors' work, which would be justified by the individuality, weight, and behavior of the animal. Barreira et al. (2002) also concluded that the incidence of tendinitis is associated with training intensity and pace.

The mean value of the cross-sectional area of the both SDFT of the horses in this study at the beginning of the training was $94.08 \mathrm{~mm}^{2}$ in the group that underwent complementary training on the treadmill and $93.42 \mathrm{~mm}^{2}$ in the group that underwent standard training at the Brazilian Army's Riding School. After the entire training phase, the mean values found for the group that underwent training was $89.77 \mathrm{~mm}^{2}$ and $100.07 \mathrm{~mm}^{2}$ for the group that did not undergo training. 
The average value for horses with training was similar to the values found for horses of the same breed. The variation of the tendon was not found as reported by the cited authors, considering that the tendon increases its area according to training, and the results of the present study showed a decrease in area. This fact, when related to horses without training, is consistent with all variants selected by the cited authors.

The variation in the mean values of the DDFT cross-sectional area was similar in horses with and without additional training; that is, they presented mean values according to the literature and an increase in area was observed due to the exercises and training adopted in this study, which matches their adaptability. The mean value of the DDFT cross-sectional area in horses at the beginning of training was $122.72 \mathrm{~mm}^{2}$ in those with complementary training and $125.92 \mathrm{~mm}^{2}$ in those with standard training at the Brazilian Army's Riding School. The observed values of the cross-sectional area of the DDFT in the horses at the end of training were $124.17 \mathrm{~mm}^{2}$ for the animals in complementary training and $126.95 \mathrm{~mm}^{2}$ for the animals with standard training at the Brazilian Army Riding School. The DDFT had higher cross-sectional area values than the SDFT, corroborating the findings of Pasin et al. (2001), Agut et al. (2009), Yamada et al. (2009), and Sousa et al. (2021). Considering the similarities and differences between the tendons evaluated by different authors, these differences can be associated with the age, size, and function of the horses.

The metacarpophalangeal joint (MF) is one of the most affected joints in horses (DE Bastiani et al., 2017; Barcelos et al.; 2012), and ultrasound is a potential diagnostic tool for examining tendons (Agut et al., 2009, Lyra et al., 2011). The level of relative fitness of an animal at the beginning of training has a large influence on the range of adaptive responses it experiences. Different genetically established muscle fiber compositions provide different types of muscle performance in response to different physical stimuli. The number and size of skeletal muscle mitochondria increase at the expense of stimuli from prolonged training (Medeiros \& Sousa, 2009).

An increase in the cross-sectional area of the tendons in the studied areas was observed when compared with the initial and final training, which is consistent with physical conditioning or adaptation. An increase was observed in all animals, certifying adaptability to the gradual training, which is the standard training and to the complementary training carried out in this study. In the thoracic limbs, the SFDT and the DDFT in all the evaluated zones presented mean values of echogenicity between 0.13 and 0.29 at the beginning of the training and values averaging between 0.17 and 0.29 at the end of training. The SDFT of the thoracic limb showed no significant difference ( $p>0.05$ ) in zones IA and IIIB with respect to the analyzed variants. In region IIB, there was a difference in the echogenicity of the SDFT between horses with and without additional training ( $\mathrm{p}=0.0362$ ). In the thoracic limb, DDFT in horses showed no difference in echogenicity in terms of training times, analysis zones, and groups of animals with and without additional training $(\mathrm{p}>0.05)$.

An increase in the transverse area of the tendons indicates acute or chronic inflammation; that is, if there are changes in shape and echogenicity, an injury at the evaluated site can be suspected (Agut et al., 2009). These lesions present with changes in echogenicity and may be hypoechoic and hyperechoic (Gillis, 1997). Pasin et al. (201) stated that under normal conditions, the DDFT has intermediate echogenicity and the SDFT is the least echogenic; therefore, the tendons have a more homogeneous texture in the absence of injury.

The interpretation of ultrasound images of tendons and ligaments considers the echogenicity, size, delimitation, shape, and position of these structures (Pasin et al., 2001). Meershoek et al. (2001a) observed that the pressures placed on the SFDT of the thoracic limb during the heel reception phase are enormous and increase with heel height and weight. In another study, Meershoek et al. (2001b) concluded that the load on the flexor tendons during reception is greater in the pelvic limb. According to Clayton (2016), the SFDT has shorter muscle fibers. Meershoek et al. (2001b) found that the height of the obstacle substantially influenced the forces in the SDFT; thus, they concluded that reducing the height of the obstacle can limit the risk of injury in the SDFT.

The SFDT widens and flattens considerably in the fetlock region, forming a fibrous ring proximal to the proximal sesamoid bones through which the DDFT runs (Alves et al., 2008). The SDFT must be strong enough to handle the high locomotor and gravitational forces it experiences and be able to stretch significantly to store sufficient amounts of energy (Alves et al., 2008; Clayton, 2016). The elevation of the jumps in relation to the joint reduces the DDFT load and increases the 
SDFT. The extension of the metacarpophalangeal joint extends the SDFT and DDFT, including their accessory ligaments, which store kinetic and potential energy, as well as elastic energy to be released during the subsequent propulsion phase. SDFT is more commonly injured than DDFT in jumping horses (O'Sullivan, 2007). The proximal joints of limbs can contribute to the storage and release of elastic energy (Gustás et al., 2004). The percentage recovery of mechanical work by saving the elastic energy of the tendons in a canter was estimated to be $36 \%(7.4 \mathrm{~m} / \mathrm{s})$ (Hodgson et al., 2014).

According to Genovese et al. (1986), the degree of severity of lesions is classified according to their echogenicity, which may present as type 1 to 4 lesions. Type 1 lesions have the most echogenic characteristics; type 2, half anechoic and half echogenic; type 3, anechoic; and type 4, totally anechoic. Yamada et al. (2009) used a tendon echogenicity pattern similar to that used by Genovese et al. (1986), representing the lesions observed with quantitative attribution 0 for the most echoic characteristic, 1 for echoic predominance, 2 for a region that is $50 \%$ echoic and $50 \%$ anechoic, 3 for anechoic predominance, and 4 for totally anechoic regions.

The present study obtained the mean echogenicity values following the standards of Yamada et al. (2009). The authors evaluated the tendons according to the degree of injury, understanding that the degrees were established on a scale of 0-4 with values closer to 0 indicating the absence of injury. In the present study, he selected horses without tendon injuries; thus, the mean values were between the standards of 0 and 1 . The present study used horse's aged 8 to 17 years. Agut et al. (2009) noted that the relative echogenicity of SDFT and DDFT was significantly higher in horses aged 2-16 years than in horses aged 19-25 years, and no significant differences were observed between males and females. The echogenicity values observed in the present study in the SDFT were 1.01 in the IA region, 0.85 in region IIB, and 0.84 in region IIIB. In the DDFT, the values were 1.08 in the IA region, 1.11 in region IIB, and 1.07 in region IIIB. The results cited in this study are corroborated by the current study, even with the small variation that may be caused by age differences, as the echogenicity of the tendons in both studies was similar, ranging from 0.17 to 1.1.

In the pelvic limbs, both tendons had echogenicity values between 0 andl of the quantitative standard, similar to those of thoracic limbs. At the beginning of training, the tendons had a mean value of echogenicity between 0.17 and 0.63 in the superficial and deep tendons, respectively. Simultaneously, there was a variation in the mean values from 0.21 to 0.58 at the end of training for the respective tendons. The SDFT of the pelvic limb did not show any difference ( $p>0.05)$ between zones IA and IIIB. In region IIB, there was a significant difference between animals with and without additional training in their respective training times $(\mathrm{p}=0.0362)$. The SDFT of the pelvic limbs showed no difference ( $p>0.05$ ) in the IA and IIB zones; however, there was a difference between the beginning and the end of training ( $\mathrm{p}=0.0284$ ) in the IIIB region.

Bernardi et al. (2017) published data resulting from the SDFT, which was homogeneously rigid in cross sections but more rigid in the proximal region when evaluated in a longitudinal section, and similar data were found when evaluating the echogenicity of the SDFT. The proximal region of both limbs analyzed in the present study, the IA zone, presented variations for a more echoic characteristic for echoic predominance. Gillis et al. (1995) concluded that the mean echogenicity generally decreased for the SDFT and DDFT tendons from proximal to distal in the limb.

\section{Conclusions}

On ultrasonographic examination of horse limbs, there were no changes that could be attributed to SDFT and DDFT lesions. The average SDFT cross-sectional areas in horses with standard training increased from the beginning to the end of training. The mean values of the cross-sectional areas of the DDFT increased after the end of training in both groups.

The echogenicity of the tendons remained between 0 and 1 in horses of both groups. These results indicated the absence of injury. The adaptation of the tendons was attributed to the increase in area and the absence of injury during the research period.

The Brazilian Army's Riding School standard training and complementary training are safe, causing no signs of injury to the tendons of horses. It is necessary to conduct new researches and develop methods to improve the evaluation of physical conditioning of athlete horses using the jumping modality. 


\section{Acknowledgements}

CAPES - Coordination for the Improvement of Higher Education Personnel; FAPERJ - Research Support Foundation in the State of Rio de Janeiro; and CNPq - National Council for Scientific and Technological Development.

\section{Ethics statement}

The research has been approved at the Animal Use Ethics Committee of the Veterinary Institute of the Universidade Federal Rural do Rio de Janeiro with protocol number 6062121118.

\section{Financial support}

APB, ITN and BCF - Received scholarship from CAPES - Coordination for the Improvement of Higher Education Personnel. The research was supported by the National Council for Scientific and Technological Development (CNPq), n 311996/2017-5.

\section{Conflict of interests}

APB, ITN, JCP, ICF, GIB, APBB, LRL and FQA - No conflict of interest

\section{Authors' contribution}

APB-Writing; Development of methodology; preparation and writing theinitial draft; Editing manuscript. ITN, JCB, GIB - Development of methodology. BCF - Application of statistical study data. APBB, LRL- Data review. FQA - Acquisition of the financial support; Development of methodology; Review and Editing manuscript

\section{Availability of complementary results}

The authors must identify where readers can access any complementary information available, such as in an online repository or from the authors on request. We suggest consulting https:// wp.scielo.org/wp-content/uploads/Lista-de-Repositorios-Recomendados_pt.pdf. GigaScience Database (GigaDB) http://gigadb.org Open multidisciplinary repository

Place where the study was conducted: The research was carried out at LADEq - Equine Performance Evaluation Laboratory, located at the Brazilian Army's Riding School (EsEqEx), in Deodoro, Rio de Janeiro, Brazil.

\section{References}

Agut, A., Martínez, M. L., Sánchez-Valverde, M. A., Soler, M., \& Rodríguez, M. J. (2009). Ultrasonographic characteristics (cross-sectional area and relative echogenicity) of the digital flexor tendons and ligaments of the metacarpal region in Purebred Spanish horses. Veterinary journal (London, England : 1997), 180(3), 377-383. http://dx.doi.org/10.1016/j.tvjl.2008.01.012. PMid:18400531.

Alves, F. R., Bombonato, P. P., Mariana, A. N. B., Guerra, P. C., Machado, P. P., Cruz-Pinto, C. E., \& Machado Júnior, A. A. (2008). Anatomia dos tendões e ligamentos da região distal dos membros torácicos de asininos (Equus asinus) utilizados como veículo de tração animal e suas relações com a anatomia do quino doméstico. Brazilian Journal of Veterinary Research and Animal Science, 45(2), 101-108. http://dx.doi.org/10.11606/issn.1678-4456. bjvras.2008.26706.

Barcelos, L. M. C., Barreira, A. P. B., Knackfuss, F. B., Lobato, G. V. C., Rodrigues, T. N. G., Santos, M. C. S., \& Lessa, D. A. B. (2012). Exame ultrassonográfico da articulação metacarpofalangeana de equinos praticantes de polo na zona oeste do estado do rio de janeiro: Protocolo e mensurações. Veterinária e Zootecnia, 19(3), 407-415.

Barreira, A. P. B., Borges, J. R. J., Cury, L., Pitombo, C. A., \& Macahyba, R. (2002). Adaptação tendínea de equinos, frente o exercício - avaliação ultra-sonográfica. Revista Brasileira de Ciência Veterinária, 9(1), 95-97.

Bastiani, G. D., Corte, F. D. L., Kommers, G. D., Brass, K. E., Pereira, R., Cantarelli, C., \& Silva, T. M. (2017). Aspectos ultrassonográficos, anatômicos e histológicos normais da articulação metacarpofalangeana equina. Pesquisa Veterinária Brasileira, 37(10), 1165-1171. http://dx.doi.org/10.1590/s0100-736×2017001000020.

Bernardi, N. S., Avante, M. L., Simões, N. A. R., Uscategui, R. A. R., Gravena, K., Canello, V. A., Queiroz, D. J., Calciolari, K., Feliciano, M. A. S., \& Lacerda Neto, J. C. (2017). Elastografia Acoustic Radiation Force Impulse (ARFI) do tendão flexor digital superficial de equinos. Revista Acadêmica Ciência Animal,15(Supl.1), 57-58. http://dx.doi. org/10.7213/academica.15.S01.2017.28. 
Clayton, H. M. (2016). Horse species symposium: Biomechanics of the exercising horse. Journal of Animal Science, 94(10), 4076-4086. http://dx.doi.org/10.2527/jas.2015-9990. PMid:27898852.

Genovese, R. L., Rantanen, N. W., Hauser, M. L., \& Simpson, B. S. (1986). Diagnostic ultrasonography of equine limbs. The Veterinary Clinics of North America. Equine Practice, 2(1), 145-226. http://dx.doi.org/10.1016/s07490739(17)30738-1. PMid:3516322.

Genovese, R., Longo, K., Berthold, B., \& Jorgenson, J. (1997). Quantitative sonographic assessment in the clinical management of superficial digital flexor injuries in thoroughbred racehorses. In: Proceedings of the 43th Annual convention of American Association of Equine Practitioners. AEEP.

Gillis, C. L. (1997). Rehabilitation of tendon and ligament injuries. In Proceedings of the 43th Annual Convention of the American Association of Equine Practitioners (pp. 306-309). AEEP.

Gillis, C., Meagher, D. M., Cloninger, A., Locatelli, L., \& Willits, N. (1995). Ultrasonographic cross-sectional area and mean echogenicity of the superficial and deep digital flexor tendons in 50 trained thoroughbred racehorses. American Journal of Veterinary Research, 56(10), 1265-1269. PMid:8928940.

Gustás, P., Johnston, C., Roepstorff, G., Drevemo, S., \& Lanshammar, H. (2004). Relationships between fore- and hindlimb ground reaction force and hoof deceleration patterns in trotting horses. Equine Veterinary Journal, 36(8), 737-742. http://dx.doi.org/10.2746/0425164044848136. PMid:15656507.

Hodgson, D. R., McKeever, K. H., \& McGowan, C. M. (2014). Tendon, ligament, bone, and cartilage: anatomy, physiology, and adaptations to exercise and training. In D. R. Hodgson, K. H. McCkeever \& C. M. McGowan. The athletic horse principles and practice of equine sports medicine (2nd ed., pp. 202-242). Elsevier.

Lyra, V. N., Mendonça, L. B. R., \& Câmara, D. R. (2011). Avaliação ultrassonográfica de tendões flexores dos membros anteriores em equinos de vaquejada. Agrária, 6(4), 717-721. http://dx.doi.org/10.5039/agraria.v6i4a1157.

Medeiros, R. J. D., \& Sousa, M. S. C. (2009). Adaptações neuromusculares ao exercício físico: síntese de uma abrangente temática. Revista da Faculdade de Educação Física da UNICAMP, 7(1), 98-120.

Meershoek, L. S., Roepstorff, L., Schamhardt, H. C., Johnston, C., \& Bobbert, M. F. (2001a). Joint moments in the distal forelimbs of jumping horses during landing. Equine Veterinary Journal, 33(4), 410-415. http://dx.doi. org/10.2746/042516401776249570. PMid:11469776.

Meershoek, L. S., Schamhardt, H. C., Roepstorff, L., \& Johnston, C. (2001b). Forelimb tendon loading during jump landings and the influence of fence height. Equine Veterinary Journal, 33(33), 6-10. http://dx.doi. org/10.1111/j.2042-3306.2001.tb05349.x. PMid:11721571.

O'Sullivan, C. B. (2007). Injuries of the flexor tendons: focus on the superficial digital flexor tendon. Clinical Techniques in Equine Practice, 6(3), 189-197.

Oliveira, K., Fachiolli, D. F., Silva, D. A., Bueno, L. G. F., \& Moura, D. J. (2019). Rédeas pessoa e lateral ativam os mesmos músculos superficiais em equinos. Brazilian Journal of Biosystems Engineering, 13(2), 116-123. http:// dx.doi.org/10.18011/bioeng2019v13n2p116-123.

Parks, A. (2003). Form and function of the equine digit. The Veterinary Clinics of North America. Equine Practice, 19(2), 285-307, v. http://dx.doi.org/10.1016/S0749-0739(03)00018-X. PMid:14575161.

Pasin, M., Brass, K. E., Rosauro, A. C., Oliveira, F. G., Figueiró, G. M., Fialho, S. S., \& Silva, C. A. M. (2001). Caracterização ultra-sonográfica dos tendões flexores em quinos: Região metacarpiana. Arquivos da Faculdade de Veterinária da UFRGS, 29(2), 131-138.

Pugliese, B. R., Carballo, C. T., Connolly, K. M., Mazan, M. R., \& Kirker-Head, C. A. (2020). Effect of fatigue on equine metacarpophalangeal joint kinematics - a single horse pilot study. Journal of Equine Veterinary Science, 86, 102849. http://dx.doi.org/10.1016/j.jevs.2019.102849. PMid:32067670.

Sousa, W. T. N., Gonçalves, T. F., Tolentino, M. L. D. L., Santos, N. P. S., Silva Filho, M. L., \& Sousa, D. C. (2021). Avaliação ultrassonográfica dos tendões flexores dos membros anteriores em equinos de vaquejada na microrregião do Alto Médio Gurgueia, Sul do Piauí, Brasil. Revista Brasileira de Ciência Veterinária, 28(1), 9-13. http://dx.doi.org/10.4322/rbcv.2021.002.

Yamada, A. L. M., Alves, A. L. G., Hussni, C. A., Nicoletti, J. L. M., Thomassian, A., Watanabe, M. G., \& Carneiro, R. (2009). Comparação de diferentes dosesde colagenase em modelo de indução de tendinite para quinos: Estudo clínico eultrassonográfico. Ciência Rural,39(4), 1124-1130. http://dx.doi.org/10.1590/S0103-84782009005000035. 